\title{
MOBILE INDOOR AUGMENTED REALITY Exploring Applications in Hospitality Environments
}

\author{
Ana M. Bernardos, Jesús Cano, Josué Iglesias and José R. Casar \\ ETSI Telecomunicación, Universidad Politécnica de Madrid, Madrid, Spain \\ \{abernardos, jcano, josue,jramon\}@grpss.ssr.upm.es
}

\begin{abstract}
Keywords: Augmented reality, Ubiquitous computing, Mobile applications, Tourism applications.
Abstract: Augmented reality (AR) is been increasingly used in mobile devices. Most of the available applications are set to work outdoors, mainly due to the availability of a reliable positioning system. Nevertheless, indoor (smart) spaces offer a lot of opportunities of creating new service concepts. In particular, in this paper we explore the applicability of mobile AR to hospitality environments (hotels and similar establishments). From the state-of-the-art of technologies and applications, a portfolio of services has been identified and a prototype using off-the-shelf technologies has been designed. Our objective is to identify the next technological challenges to overcome in order to have suitable underlying infrastructures and innovative services which enhance the traveller's experience.
\end{abstract}

\section{INTRODUCTION}

The advances of personal mobile technologies have made possible to create new concepts to interact with the environment and the objects in it through mobile devices. In this direction, augmented reality (AR) relies on combining and superimposing virtual information over the real world, providing the user with extra (even real time) computer-based information about resources, objects or points of interest.

The 'augmented reality' concept is not new, but has been revisited since the sixties, when Sutherland (Sutherland, 1968) designed a head-mounted display tracked by both mechanical and ultrasonic trackers. Nevertheless, the term, as it is, is in use since 1992 (Caudell and Mizell, 1992). Nowadays, the generalization of high-resolution cameras and embedded compasses and inertial systems in mobile devices has created the technological breeding ground for the democratization of mobile AR services.

In this paper, we explore the possibilities of mobile augmented reality as interface with indoor (smart) spaces. In particular, we focus on the potential implementation and uses of indoor AR in tourism settings such as hotels. The paper is organized as follows. Section 2 reviews the state of the art of AR in mobile devices: technologies, applications and developing tools. Section 3 gathers some AR service concepts we are currently handling to create the Hotel of the Future in the THOFU project. Section 4 describes our design for a testbed in our lab to experiment with indoor AR. Finally, Section 5 concludes the paper with some comments on open challenges.

\section{MOBILE AUGMENTED REALITY: STATE-OF-THE-ART}

In order to deploy AR services, it is necessary to define, in real time and continuously, the spatial relationship between the user - who is carrying or wearing the visualization display - and the objects or reference points in the 'user's coverage area'. Distance and orientation between the target and the user will be principal inputs for AR service delivery.

In order to calculate this spatial relationship and track it, three types of techniques are currently used: a) those based on image recognition - vision-based tracking; b) those working on inertial and positioning data - sensor-based tracking and c) hybrid tracking, combining both methods. Readers interested in tracking technology can resort to (Zhou et al., 2008) for a wide review of existent technology.

While talking about mobile AR, the first group of techniques relies on the use of a camera to 
continuously 'snapshot' the target object and process the image to estimate the position, orientation and movement of the visualization display with respect to the target object. Direct object recognition may be difficult and unstable, but the deployment of markers improves the performance of the recognition system. Markers may be easily recognizable by the user (e.g. bidimensional codes stuck or printed on the object) or hidden inside an image. In general, lighting and focus related problems limit the performance of AR services using this approach.

The second group of techniques works with algorithms that fuse orientation, movement and location estimates from inertial and positioning systems to physically reference the user to the target object. When outdoors, GPS offers sufficient accuracy to locate the user, while compasses may provides orientation and accelerometers (and gyros, if existent) allow estimating the device's relative inclination. When indoors, radio-based positioning systems (propagation channel model or fingerprintbased ones) are usually offering an average accuracy that is not enough to deliver AR functionalities. Thus, it is necessary to switch to costly and dense infrastructures (e.g. based on ultrawideband, ultrasounds or infrared localization systems), typically complemented with user-worn devices, in order to achieve centimetre-level accuracy.

Table 1 gathers a sample of currently available mobile AR services, classified depending on the operative system they run on top of and the technology they use to estimate the relative position. As the reader may notice, some of the applications fuse the use of camera and location technologies (hybrid techniques). Most of the proposals are designed for outdoors, and when indoors they are relying in vision marker-based tracking.

With respect to the state-of-the-art of developing tools, nowadays it is possible to find proposals using a) image recognition and b) GPS information for tracking. Following there is a list of some of the available toolkits for different mobile platforms.

ARToolKit is a tool that facilitates target tracking and virtual object interaction through images; versions are available both for iPhone, Android and Windows Mobile (e.g. ARToolWorks, Studierstube Tracker), and a limited version for Java and C\# is also available (NyARToolkit). Qualcomm offers a SDK to develop Android AR applications. Still in beta, it is designed to develop image based AR applications, facilitating basic features such as identification and target tracking, and interface features, such as interaction with virtual buttons.
D'Fusion Mobile provides a platform for iPhone and Android, which allows marker-based object recognition, together with face recognition and accelerometers and localization support. Unifieye Mobile facilitates the development of AR markerbased applications for iPhone, Android, Symbian and Windows Mobile, additionally working on GPS and compass.

Table 1: Review of selected mobile AR applications. Note: POI stands for Point of Interest.

\begin{tabular}{|c|c|c|c|}
\hline & O.S. & Sensors & Description \\
\hline Layar & $\begin{array}{l}\text { iPhone, } \\
\text { Android }\end{array}$ & $\begin{array}{c}\text { GPS, } \\
\text { compass } \\
\& \text { acc. }\end{array}$ & \multirow{2}{*}{$\begin{array}{l}\text { AR browsers. } \\
\text { Info about } \\
\text { POIs. }\end{array}$} \\
\hline Wikitude & $\begin{array}{l}\text { iPhone, } \\
\text { Android, } \\
\text { Symbian }\end{array}$ & $\begin{array}{c}\text { GPS, } \\
\text { compass } \\
\text { \& acc. }\end{array}$ & \\
\hline $\begin{array}{l}\text { Google } \\
\text { Goggles }\end{array}$ & $\begin{array}{l}\text { iPhone, } \\
\text { Android }\end{array}$ & $\begin{array}{l}\text { Camera, } \\
\text { GPS }\end{array}$ & $\begin{array}{l}\text { Image-based } \\
\text { web search } \\
\text { (monuments, } \\
\text { books, brands, } \\
\text { etc.) }\end{array}$ \\
\hline $\begin{array}{c}\text { Space } \\
\text { InvadAR }\end{array}$ & $\begin{array}{l}\text { iPhone, } \\
\text { Android }\end{array}$ & Camera & AR Game \\
\hline $\begin{array}{c}\text { Google Sky } \\
\text { Map }\end{array}$ & Android & $\begin{array}{c}\text { GPS, } \\
\text { compass }\end{array}$ & \multirow{2}{*}{$\begin{array}{l}\text { Sky } \\
\text { constellations }\end{array}$} \\
\hline Star Chart & iPhone & $\begin{array}{c}\text { GPS, } \\
\text { compass }\end{array}$ & \\
\hline $\begin{array}{c}\text { Madrid } \\
\text { nearest Metro }\end{array}$ & iPhone & $\begin{array}{c}\text { GPS, } \\
\text { compass }\end{array}$ & $\begin{array}{l}\text { Nearer metro } \\
\text { stations }\end{array}$ \\
\hline Cyclopedia & iPhone & $\begin{array}{c}\text { GPS, } \\
\text { compass }\end{array}$ & $\begin{array}{l}\text { Wikipedia } \\
\text { info about } \\
\text { POIs }\end{array}$ \\
\hline $\begin{array}{l}\text { SnapShot } \\
\text { Showroom }\end{array}$ & iPhone & Camera & $\begin{array}{ll}\begin{array}{l}\text { Preview } \\
\text { furniture } \\
\text { rooms }\end{array} & \text { in } \\
\end{array}$ \\
\hline $\begin{array}{l}\text { Augmented } \\
\text { Car Finder }\end{array}$ & iPhone & $\begin{array}{c}\text { GPS, } \\
\text { compass }\end{array}$ & $\begin{array}{l}\text { Parking } \\
\text { helper }\end{array}$ \\
\hline buUuk & $\begin{array}{l}\text { iPhone, } \\
\text { Android, } \\
\text { Symbian }\end{array}$ & $\begin{array}{c}\text { GPS, } \\
\text { compass }\end{array}$ & \multirow{2}{*}{$\begin{array}{l}\text { Restaurant } \\
\text { guide }\end{array}$} \\
\hline Le Bar Guide & iPhone & $\begin{array}{c}\text { GPS, } \\
\text { compass }\end{array}$ & \\
\hline $\begin{array}{l}\text { The Virtual } \\
\text { Public Art } \\
\text { Project }\end{array}$ & $\begin{array}{l}\text { iPhone, } \\
\text { Android }\end{array}$ & $\begin{array}{c}\text { GPS, } \\
\text { compass }\end{array}$ & $\begin{array}{l}\text { Virtual } \\
\text { sculptures on } \\
\text { real settings } \\
\text { (over Layar) }\end{array}$ \\
\hline Word Lens & iPhone & Camera & $\begin{array}{l}\text { Signs } \\
\text { translator }\end{array}$ \\
\hline Mentira & iPhone & $\begin{array}{c}\text { GPS, } \\
\text { compass }\end{array}$ & $\begin{array}{l}\text { AR game to } \\
\text { learn Spanish }\end{array}$ \\
\hline
\end{tabular}

The Layar browser, available both for iPhone and Android, can be used to create new AR applications based in GPS. This tool is only suitable to customize the information about points of interest available in 
Layar. Mixare, Wikitude and junaio are similar alternatives to Layar for Android and/or iPhone. Wikitude provides an API that allows integrating its localization system in an external application. ARIS (Augmented Reality and Interactive Storytelling) is an open source tool to create outdoors AR educational games. For Windows Phone 7, the available SDK for Visual Studio and its documentation makes possible to access embedded sensors (accelerometers and GPS), although it is not possible to access the camera. This restriction does not exist in previous versions of Windows Mobile. Mono allows using $\mathrm{CH}$ code in environments which are not originally prepared for that, e.g. iPhone, without losing control over the device's APIs. It is an alternative when using $\mathrm{C \#}$ is an option either for efficiency, knowledge or reusability.

Most of the available tools are designed for iPhone or Android. For any of these operative systems, the choice depends on the type of target application. Our objective is to apply mobile AR concepts to be used indoors, in a very defined domain. Next Section details the type of applications we are considering.

\section{INDOOR MOBILE AR APPLICATIONS FOR HOSPITALITY SETTINGS}

The THOFU project (Technologies for the HOtel of the FUture) is a cooperative Spanish research project; 35 entities research technologies that may serve to configure a new offering of context-aware user-centric services in advanced hospitality infrastructures. Within this application framework, $\mathrm{AR}$ is considered to be a relevant concept enabling to build a new service offering.

To date, commercial mobile AR applications for tourists are ready to be used outdoors. For example, the Museum of London is providing StreetMuseum, an iPhone application superimposing information about old London all over the city. When facing indoors, to the best of our knowledge experiences are still prototypes (limited in time and space): for example, the iTacitus project has delivered AR applications for the Palace of Venaria in Turin (Zoellner et al., 2009) - to see how frescos on the walls once appeared - or to show how the court inside the Winchester castle was. The Louvre-DNP Museum Lab Project has resulted in an UltraMobile-PC AR museum guide using markerless tracking (based on Ubisense ultrawideband) (Miya- shita et al., 2008).

THOFU aims at exploring the possibilities of AR in hotels to enhance the visitor's experience, in order to:

- Become familiar with the room: mobile AR may be used to provide additional information about standard objects in hotel's rooms. The guest may use an AR application to discover resources in the room, for example where the strongbox is located. The fixline phone may be augmented with its agenda and additional information about pricing; the television may be augmented with the programmes and the pay TV offer. Pillows may show the pillow menu, soaps and gels may show their composition and furniture or decorations may offer information about their design or even information about how to acquire them. Additionally, AR may enhance the way we interact with smart home controls, e.g. allowing to visualize the room temperature in graphical mode and modify it when pointing the mobile device to the air conditioning.

- Improve Access to Safety \& Emergencies Information: the traveller may receive information about the electricity system when pointing at a plug (voltage, connector type, where to acquire a current adaptor, etc.). Information about emergency wayouts and procedures may be easily consumed on an AR application too.

- Facilitate Navigation in Complex Environments: Virtual sings may be superimposed to real views to guide the user towards his destination. It is important to note that the navigation system should perform well both indoors and outdoors, and even in special areas such as parkings. Combined with geotagging, AR navigation may offer services such as car search. The combination with a well-situated marker catalogue - which may facilitate searching or typing the destination - may enhance the application use.

- Offer a Different Service Experience: mobile AR makes possible to offer additional information about the available dishes in a menu, their composition or their nutritional features. For example, it is possible to visualize the menu when pointing at the table or the drink offer by pointing at the bar.

- Provide Configurable Virtual Decoration. For example, virtual exhibitions may be offered in some spaces of the hotel. These exhibits will need to be 'visited' through the mobile device. Additionally, the guest may have the option of virtually refurbishing some customizable items in his room, in order to attach virtual data to real objects (e.g. the user may want to check the weather when pointing some objects in the room). 
- Facilitate Interaction between Staff and Clients and Improve Processes: face recognition-based AR applications may speed checking up by helping the staff to recognize frequent customers' faces in order to personalize treatment.

- Motivate the User to Discover the Hotel Surroundings: from balconies and terraces mobile AR applications may serve to visualize nearby resources and tourism information.

Additionally, it is possible to deliver mobile AR applications for maintenance tasks. For example, the sensing infrastructure may be controlled through an application visualizing the state and the levels from sensors just superimposed on the real world where they are deployed.

With these applications in mind, we want to configure a testbed to try new mobile AR concepts (for hospitality) on top of off-the-shelf underlying technologies. Next section describes our technological choice and first trials.

\section{PROTOPYTING AN INDOOR AR TESTBED}

Our final objective is to build up an indoor AR sensor-based testbed. The system should recognize tagged objects and points of interest (PoIs) to enable the list of applications in the previous section. We do not discard to combine the solution with visionbased complementary algorithms to enhance the system performance, but we firstly focus on setting up a solution for the sensor-based approach. If accurate, we consider that it is much easily scalable (e.g. including new PoIs does not require any extra modification of the algorithm base) than the visionbased one. Additionally, it can set up the basis for new interaction schemas (e.g. pointing computing) helping to spread AR use.

From the review of developing tools, we have chosen to use the open source Mixare. Mixare works over Android. We have opted for Android due to its standard, easy and well documented APIs to access sensors, apart from the availability of advanced hardware and the growing market share.

We have modified its native GPS localization API to make it work with our indoor positioning systems. PoIs have been included in JSON format (JavaScript Object Notation, a light format for data exchange) in a file, adapting them to use the available standard method to load information in Mixare.

Mixare works on WGS84 datum to represent co- ordinates (the system used by GPS receivers). The coordinates of the PoIs have been integrated in GPS format in order to handle them with default methods (nevertheless, some conversions from UTM to GPS have been needed).

Finally, interface methods have been modified to adapt the position of the plotted markers referencing PoIs in order to enhance visualization. Figure 1 contains a screenshot of the application deployed over a HTC Hero Android device, showing the name of the POIs and the estimated distance to the visualization device.

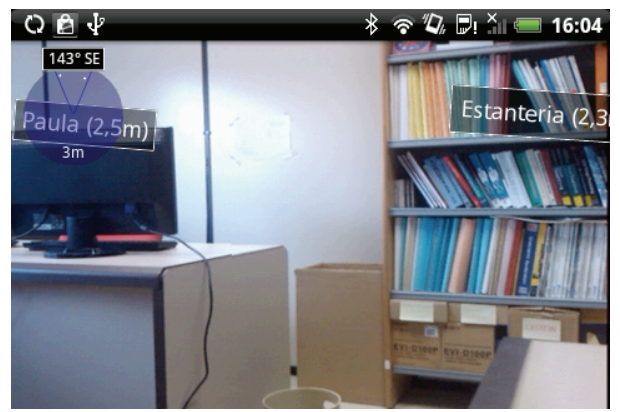

Figure 1: Screenshot of our indoor AR object tagging application based on Mixare.

As previously stated, indoor AR applications are very demanding in terms of accuracy - errors are easily perceived by the user (distances are shorter and easy to estimate); thus, service experience may be ruined if underlying localization technologies underperform. Our RF positioning systems - based on WiFi, ZigBee and Bluetooth, see e.g. (Aparicio et al., 2008) - provide enough accuracy to perform reliable estimation of the zone/area where the user is staying (error varies between 2 and 3 meters). As this solution is not suitable for indoor AR and we are looking for a non-pricey infrastructure with minimum hardware needs, we initially have opted to deploy a set of reference positions from which the user is capable of getting the information of all the tagged PoIs around him. These positions identified by pressure mats connected through a ZigBee communication channel to a sensor network covering the deployment area. Of course, this is a suboptimal solution because it limits the service availability and restricts natural interaction, but it allows handling concept testing.

\section{CONCLUSIONS}

Most of commercial AR applications have been designed to work outdoors, while indoor settings 
present new challenges not only for accurate positioning, but also for the AR application concept itself.

The lack of stable and accurate indoor location estimation usually requires ad-hoc localization deployments, typically expensive and still unfeasible in normal settings. For this reason, it is possible to think that the most adequate approach to adopt for indoor $\mathrm{AR}$ is vision-based. Nevertheless, these systems are unstable enough to require the user to make several attempts (focusing the mobile camera once and again) before getting a satisfactory result (due to light, camera diversity and user skills). Apart from that, they usually require to deploy markers to guarantee good detection. Markerless tracking is still an open challenge.

Considering scalability, vision-based techniques scale worse than sensor-based ones, as recognizing a new object requires to have it characterized in the image database. Additionally, image search is usually a resource-consuming task, which may have to be performed (or supported) by an external infrastructure.

Then, even if a reasonable amount of contextaware services may perform well using symbolic location, there is still a clear need for accurate inexpensive indoor positioning systems to implement sound AR services. As embedded inertial systems are increasing their quality and diversity (gyroscopes have been recently included in some mobile devices), the solution may rely on fusing data coming from many sources of information, which may be opportunistically deployed depending on the environment.

Using mobile AR should represent a step forward towards natural interaction, so the services to be built on it should make a difference to other interface options. Exploring new interaction concepts to capture the real objects or POIs - such as using the mobile device as a remote control (not needing to use the camera) - may facilitate user adoption.

\section{ACKNOWLEDGEMENTS}

This work is being supported by the Government of Madrid under grant S2009/TIC-1485 and the Spanish Ministry for Science and Innovation under grant TIN2008-06742-C02-01. Additionally, the application area is motivated by the THOFU CENIT Project, funded by the Centre for the Development of Industrial Technology.

\section{REFERENCES}

Aparicio, S., Pérez, J., Bernardos, A. M., Casar, J. R., 2008, A fusion method based on Bluetooth and WLAN Technologies for Indoor Location, IEEE Int. Conf. in Multisensor Fusion and Integration for Intelligent Systems, Seoul.

Caudell, T. P., Mizell, D. W., 1992, Augmented Reality: An Application of Heads-Up Display Technology to Manual Manufacturing Processes, Proceedings of 1992 IEEE Hawaii International Conference on Systems Sciences, pp 659-669.

Feng, Z., Duh, H. B.-L., Billinghurst, M., 2008, Trends in augmented reality tracking, interaction and display: A review of ten years of ISMAR, 7th IEEE/ACM International Symposium on Mixed and Augmented Reality, pp. $193-202$.

Mixare, http://www.mixare.org

Miyashita, T., Meier, P., Tachikawa, T., Orlic, S., Eble, T., Scholz, V., Gapel, A., Gerl, O., Arnaudov. S., Lieberknecht, S., 2008, An Augmented Reality Museum Guide, Proceedings of the 7th IEEE/ACM International Symposium on Mixed and Augmented Reality, pp. 103-106.

Sutherland, I., 1968, A Head-Mounted Three Dimensional Display, Proceedings of Fall Joint Computer Conference, pp. 757-764.

THOFU, http://www.thofu.es

Zoellner, M., Keil, J., Drevensek, T., Wuest, H., 2009, Cultural Heritage Layers: Integrating Historic Media in Augmented Reality, $15^{\text {th }}$ International Conference on Virtual Systems and Multimedia, pp. 193-196. 